\title{
Carving a niche for immunotherapy in ovarian cancer
}

\section{Nitasha Gupta, Erika Lampert and Jung-Min Lee}

Ovarian cancer is one of the most aggressive women's cancers and is difficult to treat in its advanced stages, where tumor recurrence and chemotherapy resistance are commonplace. As such, clinical trials with novel drug combination strategies including PARP inhibitors and immune checkpoint blockade (ICB) have proliferated to address this unmet clinical need. A recent study published in Clinical Cancer Research by Lampert et al. describes the efficacy, tolerability, and biomarker evaluation from a proof-of-concept phase II trial of the anti-PD-L1 antibody durvalumab and a PARP inhibitor olaparib in 35 patients with recurrent ovarian cancer based on positive safety data and preliminary antitumor activity from a phase I trial $[1,2]$. Such drug combinations have been hypothesized to leverage synthetic lethality as well as the tumor milieu to provide greater antitumor activity than monotherapy alone. More specifically, PARP inhibitors kill tumor cells by blocking base excision repair and trapping PARP enzymes at damaged DNA, resulting in DNA breaks and cytotoxicity, particularly in cells with underlying homologous recombination deficiency (e.g., $B R C A 1$ and BRCA2 mutations) [3]. Also, PARP inhibition has been shown preclinically to enhance PD-L1 expression and induce STING pathway activation, in addition to stimulating IFN $\gamma$ and other inflammatory cytokines, promoting a net immunostimulatory environment $[4,5]$. Thus, it was hypothesized that PARP inhibition would enhance the clinical response to ICB by producing a more immunogenic tumor microenvironment (TME).

Lampert et al. tested this hypothesis in ovarian cancer patients by evaluating clinical activity of combination durvalumab and olaparib, as well as investigating comprehensive correlative endpoints using tissues and blood samples. Moreover, it was the first ICB trial in ovarian cancer to collect fresh pre- and ontreatment tumor core biopsies, enabling a more accurate representation of the dynamic immune TME than archival tumor samples from primary debulking surgery or biopsies at first recurrence. In this study, neither baseline nor changes in PD-L1 expression were associated with clinical response. This result is somewhat at odds with preliminary findings in less heavily pretreated populations, requiring further prospective validation. For instance, post-hoc subgroup analysis from JAVELIN-200 (48\% with 1 prior line of therapy, 52\% with 2-3 prior lines of therapy), a randomized phase III trial looking at the antiPD-L1 antibody avelumab in combination with pegylated liposomal doxorubicin (PLD), examined 442 patients with evaluable PD-L1 expression (78\% of the total study population). Patients with PD-L1-positive tumors in the combination arm had a longer progression-free survival (PFS) than those in the PLD arm (3.7 [95\% CI 2.2-5.6] vs. 1.9 months [95\% CI 1.9-3.6]; $p=0.0048$ ), while patients in the PD-L1-positive subgroup of the avelumab arm did not demonstrate longer PFS relative to those within the PLD arm [6]. Similarly, KEYNOTE-100 (76\% $\leq 2$ prior therapies, 24\% 3-5 prior therapies), a single-arm phase II trial evaluating pembrolizumab monotherapy, reported a trend toward increased objective response rate (ORR) with a higher combined positive score (CPS) of tumor and immune PD-L1 staining (13.8\% [95\% CI 6.5-24.7] in CPS $\geq 10$ vs. $7.3 \%$ [95\% CI 3.4-13.3] in CPS $<1$; $p=$ ns), although overall ORR in all-comers was still modest at $8.5 \%(95 \%$ CI $5.9-11.8)[7,8]$.

Though preclinical studies suggest that PARP inhibition induces STING pathway activation and increases tumor mutational burden (TMB), Lampert et al. reported no significant changes in TMB or STING expression with treatment, suggesting that both mechanisms are unlikely drivers of clinical response to ICB, consistent with findings in other cancers as well $[4,9,10]$. Optimal measurement of STING pathway activation is challenging, and the clinical value of its measurement is to be determined. Instead, Lampert et al. found that treatment induced several immunostimulatory changes, including increased mRNA expression of $I F N \gamma$ and IFN $\gamma$-induced chemokines CXCL9 and CXCL10; systemic production of IFN $\gamma$ and $\mathrm{TNF} \alpha$; and tumoral infiltration by lymphocytes. Enhanced plasma IFN $\gamma$ protein levels were associated with response and improved PFS. Baseline expression of an IFN $\gamma$-related gene signature by RNA-seq analysis was also associated with clinical benefit. Similar findings were observed in TOPACIO, in which mutational signature 3 and IFN-signaling in the CD8+ T-cell compartment of the TME were identified as possible biomarkers of clinical response to niraparib plus pembrolizumab [11, 12].

Notably, Lampert et al. found an increase in angiogenic factors (e.g., VEGFR3) on-treatment, which may have contributed to the poor ORR through immunosuppression by activation of myeloid-derived suppressor cells and regulatory $\mathrm{T}$ cells, while reducing the activity of antigen-presenting cells and effector $\mathrm{T}$ cells [13]. This finding is supportive of triplet approaches including PARP inhibitors, ICB, and VEGF/VEGFR inhibitors. A phase I/II study combining olaparib, 
Table 1: Recently published or reported studies evaluating the combination of ICB with other agents in ovarian cancer

\begin{tabular}{|c|c|c|c|c|c|}
\hline Study & Disease & Immunotherapy & Combined with & $\begin{array}{l}\text { ORR/DCR, \% } \\
(95 \% \text { CI })\end{array}$ & $\begin{array}{l}\text { PFS/OS, mos } \\
(95 \% \text { CI })\end{array}$ \\
\hline $\begin{array}{l}\text { TOPACIO } \\
\text { NCT02657889 } \\
\text { Single arm } \\
\text { Phase I/II } \\
\text { Konstantinopoulos et al. } 2019 \text { [11] }\end{array}$ & $\begin{array}{l}60 \text { evaluable patients } \\
\text { Recurrent setting } \\
30 \text { platinum-resistant } \\
17 \text { platinum-refractory } \\
15 \text { platinum-toxicity/allergy } \\
\\
49 \text { patients with } B R C A w \mathrm{wt} \\
9 B R C A \mathrm{~m} \\
2 B R C A 2 \mathrm{~m}\end{array}$ & Pembrolizumab & Niraparib & $\begin{array}{l}\text { ORR: } 18 \%(11-29) \\
3 \mathrm{CR}, 8 \mathrm{PR} \\
\text { DCR: } 65 \%(54-75) \\
28 \mathrm{SD}\end{array}$ & OS: Not reported \\
\hline $\begin{array}{l}\text { MEDIOLA } \\
\text { NCT02734004 } \\
\text { Single arm } \\
\text { Phase II } \\
\text { Drew et al. } 2019 \text { ESMO Congress [15] }\end{array}$ & $\begin{array}{l}32 \text { evaluable patients } \\
\text { Recurrent setting } \\
\text { Platinum-sensitive } \\
22 B R C A 1 \mathrm{~m} \\
10 B R C A 2 \mathrm{~m}\end{array}$ & Durvalumab & Olaparib & $\begin{array}{l}\text { ORR: } 71.9 \%(53.25-86.25) \\
7 \mathrm{CR}, 16 \mathrm{PR} \\
\text { DCR at } 28 \text { weeks: } 65.6 \%(49.6-79.4)\end{array}$ & $\begin{array}{l}\text { PFS: } 11.1 \operatorname{mos}(8.2-15.9) \\
\text { OS: Not reported }\end{array}$ \\
\hline $\begin{array}{l}\text { KEYNOTE-100 } \\
\text { NCT02674061 } \\
\text { Single arm } \\
\text { Phase II } \\
\text { Matulonis et al. } 2020 \text { ASCO Meeting [8] }\end{array}$ & 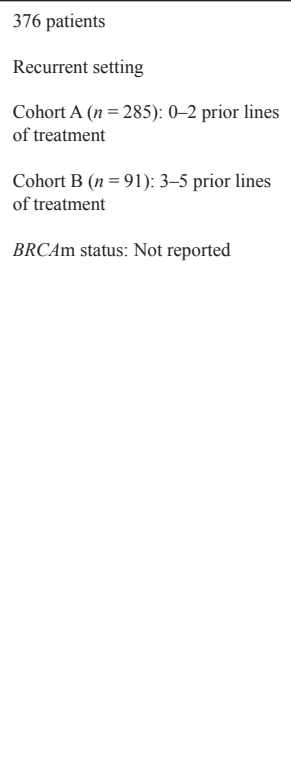 & 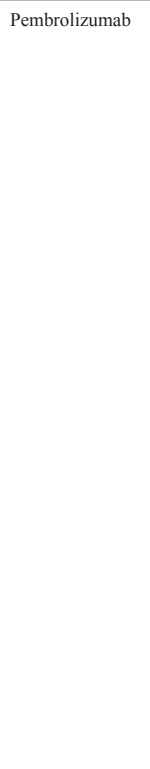 & 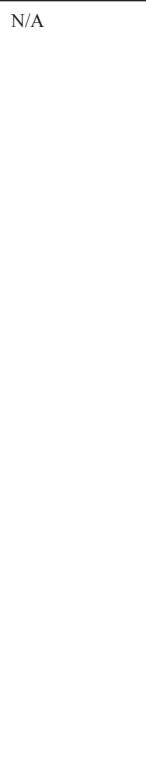 & $\begin{array}{l}\text { ORR combined } \\
\text { Total: } 8.5 \%(5.9-11.8) \\
\text { CPS } \geq 10: 13.8 \%(6.5-24.7) \\
\text { CPS } \geq 1: 8.0 \%(4.2-13.6) \\
\text { CPS }<1: 7.3 \%(3.4-13.3) \\
\text { ORR cohort A } \\
\text { Total: } 8.1 \%(5.2-11.9) \\
\text { CPS } \geq 10: 11.6(3.9-25.1) \\
\text { CPS } \geq 1: 6.9(2.8-13.8) \\
\text { ORR cohort B } \\
\text { Total: } 9.9 \%(4.6-17.9) \\
\text { CPS } \geq 10: 18.2(5.2-40.3) \\
\text { CPS } \geq 1: 10.2(3.2-22.2) \\
\text { DCR combined } \\
\text { Total: } 22.1 \%(18.0-26.6) \\
\text { CPS } \geq 10: 27.7 \%(17.3-40.2) \\
\text { CPS } \geq 1: 24.0 \%(17.4-31.6) \\
\text { DCR cohort A } \\
\text { Total: } 22.1 \%(17.4-27.4) \\
\text { CPS } \geq 10: 25.6 \%(13.5-41.2) \\
\text { CPS } \geq 1: 24.8 \%(16.7-34.3) \\
\text { DCR cohort B } \\
\text { Total: } 22.0 \%(14.0-31.9) \\
\text { CPS } \geq \mathbf{1 0}: 31.8 \%(13.9-54.9) \\
\text { CPS } \geq 1: 22.4 \%(11.8-36.6) \\
\text { None of the above subgroup analyses } \\
\text { reached statistical significance }(p<0.05)\end{array}$ & $\begin{array}{l}\text { PFS cohort A } \\
\text { Total: } 2.1 \operatorname{mos}(2.1-2.2) \\
\text { CPS } \geq 10: 2.1 \operatorname{mos}(2.1-4.2) \\
\text { CPS } \geq 1: 2.1 \operatorname{mos}(2.1-2.8) \\
\text { PFS cohort B } \\
\text { Total: } 2.1 \operatorname{mos}(2.1-2.6) \\
\text { CPS } \geq 10: 2.1 \operatorname{mos}(2.0-8.3) \\
\text { CPS } \geq 1: 2.1 \operatorname{mos}(2.1-3.3) \\
\text { OS cohort A } \\
\text { Total: } 18.7 \text { mos }(17.0-22.5) \\
\text { CPS } \geq 10: 21.9 \operatorname{mos}(12.9-26.8) \\
\text { CPS } \geq 1: 20.6 \operatorname{mos}(15.2-23.2) \\
\text { OS cohort B } \\
\text { Total: } 17.6 \text { mos }(13.3-24.4) \\
\text { CPS } \geq 10: 24.0 \text { mos }(14-\mathrm{NR}) \\
\text { CPS } \geq 1: 20.7 \text { mos }(13.6-27.4) \\
\text { None of the above subgroup } \\
\text { analyses reached statistical } \\
\text { significance }(p<0.05)\end{array}$ \\
\hline $\begin{array}{l}\text { JAVELIN-200 } \\
\text { NCT02580058 } \\
\text { Randomized } \\
\text { Phase III } \\
\text { Pujade-Lauraine et al. } 2019 \text { SGO } \\
\text { Meeting [6] }\end{array}$ & $\begin{array}{l}566 \text { evaluable patients } \\
\text { Recurrent setting } \\
424 \text { platinum-resistant } \\
142 \text { platinum-refractory } \\
\text { Avelumab + PLD }(n=188) \\
\text { Avelumab alone }(n=188) \\
\text { PLD alone }(n=190) \\
\text { BRCAm status: Not reported }\end{array}$ & Avelumab & PLD & $\begin{array}{l}\text { ORR combined: } 13.3 \%(8.8-19.0) \\
\text { ORR avelumab alone: } 3.7 \%(1.5-7.5) \\
\text { ORR PLD alone: } 4.2 \%(1.8-8.1)\end{array}$ & $\begin{array}{l}\text { PFS combined } \\
\text { Total: } 3.7 \text { mos }(3.3-5.1) \\
\text { PD-L1+: } 3.7 \text { mos (2.2-5.6) } \\
\text { PD-L1-: } 3.9 \text { mos (1.9-5.5) } \\
\text { PFS avelumab alone } \\
\text { Total: } 1.9 \text { mos (1.8-1.9) } \\
\text { PD-L1+: } 1.9 \text { mos }(1.8-2.3) \\
\text { PD-L1-: } 1.8 \text { mos (1.8-1.9) } \\
\text { PFS PLD alone } \\
\text { Total: } 3.5 \text { mos (2.1-4.0) } \\
\text { PD-L1+: } 1.9 \text { mos (1.9-3.6) } \\
\text { PD-L1-: } 3.7 \text { mos (3.2-5.5) } \\
\text { OS combined: } \\
\text { Total: } 15.7 \text { mos }(12.7-18.7) \\
\text { PD-L1+: } 18.4 \text { mos }(13.7-22.0) \\
\text { PD-L1-: } 12.7 \text { mos (7.8-18.7) } \\
\text { OS avelumab alone: } \\
\text { Total: } 11.8 \text { mos }(8.9-14.1) \\
\text { PD-L1+: } 13.7 \text { mos (9.6-NE) } \\
\text { PD-L1-: } 10.5 \text { mos (6.8-15.3) } \\
\text { OS PLD alone: } \\
\text { Total: } 13.1 \text { mos (11.8-15.5) } \\
\text { PD-L1+: } 13.8 \text { mos (10.5-17.7) } \\
\text { PD-L1-: } 13.1 \text { mos (10.9-15.7) } \\
\text { None of the above subgroup } \\
\text { analyses reached statistical } \\
\text { significance }(p<0.05)\end{array}$ \\
\hline
\end{tabular}




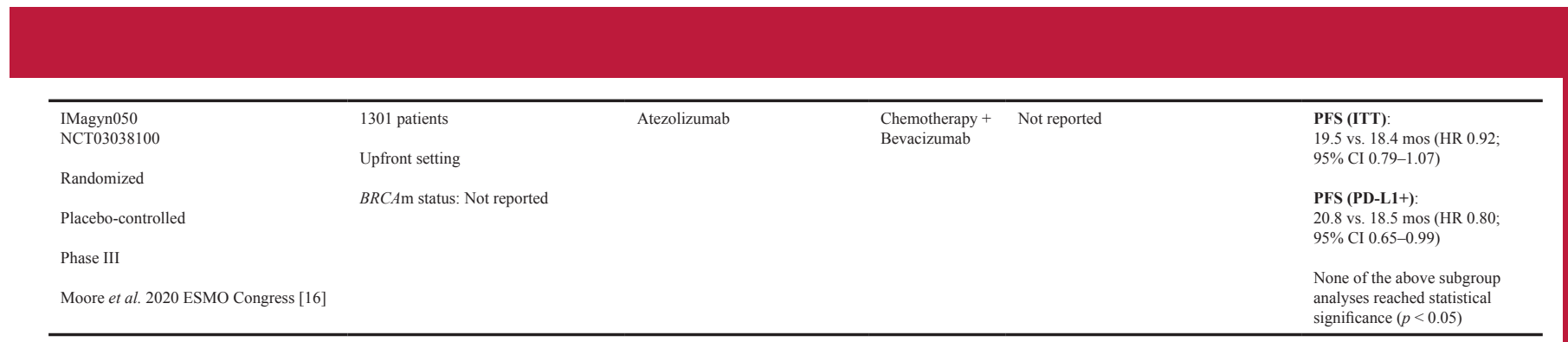

Abbreviations: BRCAwt, BRCA wild type; $B R C A I \mathrm{~m}, B R C A 1$ mutation; $B R C A 2 \mathrm{~m}, B R C A 2$ mutation; CI, confidence interval; CPS, combined positive score; CR, complete response; DCR, disease control rate; HR, hazard ratio; ITT, intent-to-treat; mos, months; N/A, not applicable; NE, not estimable; NR, not reached; ORR, objective response rate; OS, overall survival; PFS, progression-free survival; PLD, pegylated liposomal doxorubicin; PR, partial response; $\mathrm{SD}$, stable disease.

durvalumab, and the VEGFR1-3 inhibitor cediranib in recurrent ovarian cancer is ongoing (NCT02484404), and a multicenter randomized phase II trial comparing triplet therapy with standard-of-care chemotherapy and other targeted drugs in platinum-resistant ovarian cancer is opening in 2021 (NRG GY-023).

The study by Lampert et al. adds to a growing list of ICB plus PARP inhibitor or chemotherapy clinical trials in ovarian cancer in which ORR (complete response [CR] + partial response [PR]) is more modest than expected if the drugs were working synergistically (Table 1). That said, ORR per Response Evaluation Criteria in Solid Tumors (RECIST) may not always be the optimal indicator of clinical benefit depending on the underlying cancer and therapeutic agents used. For instance, ICB may display atypical response patterns, such as delayed tumor size reduction, mixed response, or an initial tumor burden increase due to pseudoprogression [14]. MEDIOLA is the exception with an ORR of $72 \%$, likely due to its platinumsensitive, PARP inhibitor-naïve, $B R C A$-mutant population who is intrinsically more responsive to PARP inhibition alone [15]. The $71 \%$ disease control rate (DCR; CR + PR + stable disease [SD]) and $34 \%$ clinical benefit rate (PR $+\mathrm{SD} \geq 6$ months) Lampert et al. reported is therefore notable, especially given the nature of this difficult-to-treat population ( $86 \%$ platinum-resistant, $52 \%$ with $\geq 4$ prior therapies, $77 \% B R C A$ wild type).

Lastly, ascertaining the optimal time for introduction of ICB in the life cycle of ovarian cancer treatment is a matter of intense scientific scrutiny, and attention must be paid to predictive biomarkers and clinical benefit previously discussed. Clinical trials in the upfront setting often operate under the notion that there are more immunoreactive cells earlier in the course of disease, rendering ICB more effective. However, whether this assumption is correct remains to be seen. Preliminary results from IMagyn050 presented at the 2020 ESMO meeting showed no improvement in PFS with the antiPD-L1 antibody atezolizumab in the intent-to-treat or PD-L1-positive population in the upfront setting, calling into question both the first-line setting as well as PD-L1 as a predictive biomarker [16]. Another key consideration is primary platinum resistant/refractory disease present in about $20 \%$ of newly diagnosed patients, in which patients progress within 6 months after completing firstline platinum-based therapy or fail to respond to first-line treatment [17]. It is likely that at least some degree of the lack of response to ICB in the upfront setting is attributable to this intrinsic resistance to chemotherapy, which has unique molecular and clinical characteristics. Furthermore, ovarian carcinoma with a "cold" immunosuppressive TME may preclude any response to immunotherapy at all [18]. Therefore, the conventional approach of incorporating ICB based on the presumed favorable immunostimulatory TME may not be applicable to a sizable proportion of patients in the upfront setting. Separate multi-cohort and multi-arm treatment trial approaches for primary platinum resistant/refractory disease, as well as a closer investigation into biomarkers and the TME of this unique subgroup, are warranted.

Immune checkpoint inhibitors, though promising in several cancers, have shown relatively limited activity thus far in ovarian cancer. The full significance of the TME in determining response to immunotherapy combination approaches has yet to be elucidated, and incorporating fresh paired tumor biopsies into clinical trials is an important step in that direction. Future studies must prioritize identification of biomarkers of response and resistance in order to better guide where in the treatment life cycle ICB therapies will yield greatest effect, as well as which population will most benefit. Such correlative studies are crucial in bridging the gap between preclinical promise and clinical success, ultimately moving the needle forward in ovarian cancer treatment.

\section{CONFLICTS OF INTEREST}

Authors have no conflicts of interest to declare.

Jung-Min Lee: Women's Malignancies Branch, Center for Cancer Research, National Cancer Institute, Bethesda, Maryland, USA

Correspondence to: Jung-Min Lee, email leej6@mail.nih.gov

Keywords: immunotherapy; PARP inhibitor; ovarian cancer; combination therapy

Received: December 10, 2020

Published: January 05, 2021 


\section{REFERENCES}

1. Lampert EJ, et al. Clin Cancer Res. 2020; 26:4268-4279. https://doi.org/10.1158/1078-0432.ccr-20-0056. [PubMed]

2. Lee JM, et al. J Clin Oncol. 2017; 35:2193-202. https://doi. org/10.1200/jco.2016.72.1340. [PubMed]

3. D'Andrea AD. DNA Repair (Amst). 2018; 71:172-6. https://doi.org/10.1016/j.dnarep.2018.08.021. [PubMed]

4. Ding L, et al. Cell Rep. 2018; 25:2972-80. https://doi. org/10.1016/j.celrep.2018.11.054. [PubMed]

5. Jiao S, et al. Clin Cancer Res. 2017; 23:3711-20. https:// doi.org/10.1158/1078-0432.ccr-16-3215. [PubMed]

6. Pujade-Lauraine E, et al. Gynecol Oncol. 2019; 154:21-2. https://doi.org/10.1016/j.ygyno.2019.04.053.

7. Matulonis UA, et al. Ann Oncol. 2019; 30:1080-7. https:// doi.org/10.1093/annonc/mdz135. [PubMed]

8. Matulonis UA, et al. J Clin Oncol. 2020; 38:6005. https:// doi.org/10.1200/JCO.2020.38.15 suppl.6005.

9. Chan TA, et al. Ann Oncol. 2019; 30:44-56. https://doi. org/10.1093/annonc/mdy495. [PubMed]

10. Fenerty KE, et al. J Immunother Cancer. 2018; 6:133-46. https://doi.org/10.1186/s40425-018-0445-4. [PubMed]

11. Konstantinopoulos PA, et al. JAMA Oncol. 2019; 5:1141-9. https://doi.org/10.1001/jamaoncol.2019.1048. [PubMed]
12. Färkkilä A, et al. Nat Commun. 2020; 11:1459. https://doi. org/10.1038/s41467-020-15315-8. [PubMed]

13. Fukumura D, et al. Nat Rev Clin Oncol. 2018; 15:325-40. https://doi.org/10.1038/nrclinonc.2018.29. [PubMed]

14. Wolchok JD, et al. Clin Cancer Res. 2009; 15:7412-20. https://doi.org/10.1158/1078-0432.ccr-09-1624. [PubMed]

15. Drew Y, et al. Ann Oncol. 2019; 30:v485-6. https://doi. org/10.1093/annonc/mdz253.016.

16. Moore KN, et al. Ann Oncol. 2020; 31:S1161-2. https://doi. org/10.1016/j.annonc.2020.08.2261.

17. Colombo N, et al. Ann Oncol. 2019; 30:672-705. https:// doi.org/10.1093/annonc/mdz062. [PubMed]

18. Le Saux O, et al. Semin Cancer Biol. 2020 Sep 12. https://doi. org/10.1016/j.semcancer.2020.08.017. [ubMed] [Epub ahead of print].

Copyright: () 2021 Gupta et al. This is an open access article distributed under the terms of the Creative Commons Attribution License (CC BY 3.0), which permits unrestricted use, distribution, and reproduction in any medium, provided the original author and source are credited. 